\title{
Fused in Sarcoma (FUS) Expression May Predict Survival Outcomes of Patients With Advanced Squamous Cell Cervical Carcinoma
}

\author{
Ana Maria Dias Fachini \\ State University of Campinas (UNICAMP) \\ Luís Otávio Sarian \\ State University of Campinas (UNICAMP) \\ Maria Cecília Ramiro Talarico \\ State University of Campinas (UNICAMP) \\ Rafaella Almeida Lima Nunes \\ São Paulo State University \\ Larissa Bastos Eloy Costa \\ State University of Campinas (UNICAMP) \\ Antonio Carlos Zuliani \\ State University of Campinas (UNICAMP) \\ Lara Termini \\ São Paulo State University \\ Silvia Helena Rabelo-Santos \\ Federal University of Goias (UFG) \\ Luiz Carlos Zeferino ( $\nabla$ zeferino@unicamp.br) \\ State University of Campinas (UNICAMP)
}

\section{Research Article}

Keywords: Fused In Sarcoma, cervical cancer, prognosis, long-term follow-up data

Posted Date: September 1st, 2021

DOI: https://doi.org/10.21203/rs.3.rs-841588/v1

License: (c) (i) This work is licensed under a Creative Commons Attribution 4.0 International License. Read Full License 


\section{Abstract}

Because of its role in preserving DNA/RNA stability, there is an increasing number of studies addressing the relationship between Fused in Sarcoma (FUS) expression and cancer. However, the disparity in FUS/FUS oncogenic vs. tumor-suppressive roles may be attributed to the complex molecular pathways associated with FUS regulation in different cancer types, and its role in cervical carcinogenesis remains largely unexplored. Methods: We determined FUS protein expression in specimens of 61 patients with advanced cervical cancer. Longterm (> 10 years) clinical follow-up data for these patients were available, and we determined disease-free, cancer-related and overall survival as related to FUS expression. Results: There were no significant associations between FUS expression and patients' age, tumor grade, and acute/late toxicity events related to treatment (either radiation alone or chemoradiation). However, multivariate Cox regression analysis for disease-free survival (recurrence), overall survival (death) and cancer-related survival showed that patients with high average FUS expression fared significantly better than their counterparts with low average FUS expression, both in terms of disease-free survival $(\mathrm{HR}=0.31 ; 95 \% \mathrm{Cl} 0.12$ to $0.77 ; \mathrm{p}=0.01)$ and cancer-related survival $(\mathrm{HR}=0.41 ; 95 \% \mathrm{Cl} 0.17$ to $0.98 ; \mathrm{p}=0.04)$. Conclusions: Our study shows that high FUS protein expression in advanced cervical cancer specimens is a potent harbinger of better prognosis, and can as such be used in clinical practice to help characterize patients and, possibly, plan treatment and follow-up strategies.

\section{Introduction}

RNA metabolism and DNA repair are regulated by several genes $(1,2)$. In this context, the Fused in Sarcoma (FUS) oncogene, located on chromosome 16 and initially idendified in human liposarcoma, has been described to encode a 526 amino acid DNA/RNA binding protein which seems to be involved in gene transcription, RNA transport and translation (3). Of special interest in oncology, it seems that FUS helps safeguard genomic stability; during DNA damage repair, FUS is one of the proteins firstly recruited to the DNA damage site $(4,5)$. Knockdown of FUS during cell growth leads to defects in DNA damage recovery (6). Loss of FUS in the nucleus affects transcription, alternative splicing and also DNA repair (7).

Because of its role in preserving DNA stability, there is an increasing number of studies addressing the relationship between FUS expression and cancer, such as in cervical, brain (glioma), liposarcoma and lung cancers (8-11). Conflicting results, however, have been reported, depending on the particular cancer type studied and whether FUS-related mRNA, protein expression, or genomic stability are being evaluated. For instance, C-terminal mutations in FUS have been shown to explain 5-10\% of cases of familial amyotrophic sclerosis (12), but FUS mutations or SNPs were not found in 96 cases of liposarcoma (10), leading the authors of that study to assume that mutations in FUS may not play a role in sarcomagenesis. Later, one study described that elevated FUS expression was negatively associated with prognosis of patients with non-small cell lung cancer (11), and one experimental study revealed that the knockdown of FUS inhibited the viability, migration and tube formation of glioma cells (9). Further, studies on prostate and cervical cancer have suggested potential associations between FUS/FUS. Haile et al (2011) found that FUS is a co-activator of androgen receptor in prostate cancer (13), and Chen et al (2019) reported that circRNA_0000285 promotes cervical cancer by up-regulating FUS in human tissues (8).

We developed a long-term randomized clinical trial to explore the efficacy of chemoradiation versus radiation alone for the treatment of advanced (stage IIIB-FIGO 2009) (14) cervical cancer. Follow-up results covering ten years have now been published $(15,16)$. We took advantage of the vast clinical follow-up data and the availability of tumor specimens from patients included in our randomized trial to further explore the association between FUS expression and cervical cancer prognosis.

\section{Patients And Methods}

\section{Selection of cases}

For this study, we selected patients who had participated in a randomized clinical trial aimed at comparing radiotherapy alone (RT) vs. radiotherapy + cisplatin (CRT) for the treatment of advanced cervical cancer (Concomitant cisplatin plus radiotherapy and high-dose-rate brachytherapy versus radiotherapy alone for stage IIIB squamous cell cervical cancer: a randomized controlled trial) (15). This study was conducted in the Women's Hospital, State University of Campinas (São Paulo, Brazil). The protocol was approved by the hospital institutional review board on April 8, 2003 and by the local research ethics committee on September 16, 2003 (Faculdade de Ciências Médicas da Unicamp, protocol number 238/2003). All patients who met the inclusion criteria and provided written informed consent were invited to participate. The recruitment period was from September 2003 to July 2010, and patients were followed up until January 2018. For this present study, only patients with available paraffin-embedded cervical specimens were included. Trial and patient details were described elsewhere (15). Of the 147 patients originally included in the trial, only 61 had cervical material available for analysis (31 in the CRT group, 30 in RT group). Ethics approval for the present analyses was obtained from regulatory authorities in Brazil (Research Ethics

Page $2 / 10$ 
Committee approval CAAE\# 55014816.5.0000.5404, 11 December 2017). All methods were carried out in accordance with guidelines and regulations from the hospital institutional review board and Ethics Comittee. Follow-up assessments were performed every 4 months in the first 2 years following the treatment, every 6 months in the third year and therefore once a year.

\section{Immunohistochemistry assay for FUS detection}

$5 \mathrm{~mm}$ thick sections of the available samples were stained with hematoxylin and eosin (HE) to ascertain presence of cervical cancer in the examined field. Immunohistochemical reactions were performed only if cervical cancer tissue had been identified in the slide. Reactions were performed in the Cancer Innovation Laboratory, Center of Translational Research in Oncology, Cancer Institute of São Paulo (ICESP), Faculty of Medicine of University of São Paulo (FMUSP), São Paulo, São Paulo, Brazil, using an automated reaction system (Ultraview Universal DAB Detection Kit@ - Ventana Medical Systems, Inc., Roche, Tucson, Arizona). The Ventana BenchMark GX (Roche Diagnostics, Mannhein Germany) was used according to the manufacturer instructions. Rabbit polyclonal antibodies directed against FUS protein (ab 13533, Abcam, Cambridge, USA) were used in the concentration of 1:1000.

\section{Analysis of immunohistochemical reactions}

Stained slides were evaluated by a experienced pathologist (LBEC). The pathologist logged the intensity of staining and the percentage of stained cells in the representative areas of squamous cell carcinoma. Evaluation covered the ratio of stained cells to the total number of cells and staining intensity in the representative areas of squamous cell carcinoma. Staining intensity was classified as 0 (no staining), 1 (weak), 2 (moderate), or 3 (strong) (Fig. 1). Microphotographs of the 3 best fields at medium magnification (x20) were taken from the lesions in each case, obtained through a 995 Nikon digital camera. Using the open source image processing software ImageJ (17) the counting of positive cells and the total number of cells per field were carried out in each picture, to obtain the positive cell ratio in each case.

For statistical reasons, the percentage of positive cells was further categorized into $<50 \%, 50-75 \%$ and $>90 \%$. Finally, we multiplied the percentage of stained cells by staining intensity, in three distinct fields, and calculated the average of that product (hereinafter referred to as average of three fields).

\section{Statistical analysis}

In order to determine the best threshold for the average of three fields to diagnose recurrence, we produced a Receiver Operating Characteristic (ROC), with the resulting optimal cutoff point being 0.233 . This cutoff point was used in subsequent analysis to separate patients into two groups, according to the average of three fields (Low if $\leq 0.233$ and High if $>0.233$ ). In Tables 1 and 2, we compared the frequencies of key patients' and tumor characteristics as related to either staining intensity, percentage of stained cells and average expression of 3 fields using Chi-squares (or Fisher's exact test where appropriate). In Table 3, we used Cox Proportional Hazard models to evaluate the disease-free, overall survival and cancer-related survival of the patients, as related to FUS expression (average of 3 fields), age, tumor grade and trial allocation group. All calculations were performed using the R Environment for Statistical Computing (18), assuming $p<0.05$ (95\% confidence intervals) as significant.

\section{Results}

Table 1 shows FUS protein expression characteristics (staining intensity, percentage of stained cells and the average expression of 3 fields) as related to patient age, tumor grade, treatment allocation (either CRT or RT), acute and late toxicity events. There were no significant associations between any of FUS expression characteristics and the variables analysed.

In Table 2, we show the relation between FUS expression characteristics and disease outcomes. A low average FUS expression in 3 fields was marginally associated with disease relapse (57.7\% of the women with low average expression relapsed, contrasted to only $31,4 \%$ of those with high average expression) ( $p=0.07)$ and local recurrence (34.6\% vs. $11.4 \%$, respectively) $(p=0.05)$. In addition, $93.8 \%$ of the patients with low average FUS expression died due to cancer, contrasted to only $66.7 \%$ of the patients with high average FUS expression, but this association was not formally significant $(p=0.09)$.

Table 3 shows the multivariate Cox regression analysis for disease-free survival (recurrence), overall survival (death) and cancer-related survival according to patient's age, tumor grade, treatment performed and average expression of 3 fields. Patients with high average FUS expression fared significantly better than their counterparts with low average FUS expression, both in terms of disease-free survival (HR = $0.31 ; 95 \% \mathrm{Cl} 0.12$ to $0.77 ; \mathrm{p}=0.01)$ and cancer-related survival $(\mathrm{HR}=0.41 ; 95 \% \mathrm{Cl} 0.17$ to $0.98 ; \mathrm{p}=0.04)$. In addition, women allocated to the RT-only group had a worse disease-free survival compared to those allocated to the CRT group $(\mathrm{HR}=2.30 ; 95 \% \mathrm{Cl}=1.01 \mathrm{fo} 5.39 ; \mathrm{p}=$ 0.05 ). Younger ( $<50$ years) women also had a poorer prognosis contrasted to their older counterparts: disease free-survival $(H R=3.45$, $95 \% \mathrm{Cl} 1.26$ to $9.45 ; \mathrm{p}=0.01)$ and cancer-related survival $(\mathrm{HR}=3.83 ; 95 \% \mathrm{Cl} 1.41$ to $10.42 ; \mathrm{p}=0.008)$.

Page $3 / 10$ 


\section{Discussion}

After examining our long-term prospective data, we were able to infer that patients with advanced cervical cancer with high FUS expression in their pathological samples had significantly better disease-free and cancer-related survival probabilities compared to those without a high FUS expression level. Other factors associated with survival were age $<50$ years and being treated with radiotherapy alone, but the association between FUS expression and survival persisted even after adjustments for age and the treatment allocation. We also found that FUS expression must be determined at several hotspot expression points, since only when examining the average expression of 3 fields we obtained a significant association with survival.

Some previous studies focused on the laboratorial aspects of FUS interaction with cancer (19-21), and less than a handful examined the clinical implications of FUS expression. In this regard, our study is a major stride towards understanding whether FUS protein expression may be used as a tool to prognosticate cervical cancer, since we used a large clinical database on prospectively followed cervical cancer patients to evaluate whether the molecule bore a relationship with survival.

It is important to highlight that our results somewhat contradict previous laboratory findings on how FUS operates in cervical cancer.

Recently, a Chinese study showed that the expression level of FUS was positively correlated with the expression of circRNA_0000285 and, subsequently, that the knockdown of circRNA_0000285 significantly inhibited the formation and metastasis of cervical cancer in nude mice. We must emphasize, however, that those authors did not test for a direct relationship between FUS expression at the protein level and cervical cancer proliferation and metastasis (8). On the other hand, in an attempt at summarizing data about FUS gene expression in association with prostate cancer, Ghanbarpanah and cols. (22) reported that FUS may prevent the growth of prostate cancer cells by down-regulating proliferator factors such as Cdk6 and cyclin D1, and up-regulating Cdk and p27. Further, an immuno-histochemical analysis showed that FUS expression had an inverse relationship with the degree of prostate cancer, which in turn suggests that patients whose tumors have a high FUS expression may experience less bone pain and theoretically enjoy a longer survival. These findings are in alignment with those from a study on cell cultures published in 2010 (23), in which the authors posited that FUS has some features of a putative tumor suppressor: FUS overexpression promoted growth inhibition and apoptosis of prostate cancer cells, whereas its knockdown led to prostate cancer cell proliferation.

Two studies on hepatocarcinoma have also suggested a positive association between FUS expression and better prognosis. Ma and colleagues (24) examined the association between miR-378 expression and liver cancer cell migration using real-time quantitative PCR, and found that miR-378 overexpression enhanced cell proliferation, migration and liver cell invasion by down-regulating Fus expression. Further, Bao and colleagues (25) examined the effects FUS has on hepatocellular carcinoma progression in HuH7 and MHCC97 cells, and found that overexpression of FUS decreased cell viability, migration, invasion and stemness, in addition to activating the Hippo pathway, which in turn is an important signaling pathway that regulates organ growth and tissue size (26). All those phenomena associated with FUS overexpression resulted in significant inhibition of hepatocellular carcinoma progression.

The small sample size is a weakness of this study because it prevented the analysis of more variables, such as other prognostic factors. However, this study showed a clear statistical association between FUS expression and the prognosis of cervical cancer, which strongly suggests the existence of a relevant biological event. This notwithstanding, further studies with large patient cohorts are need to confirm the results of this work.

In synthesis, our study suggests an important association between FUS protein expression and cervical cancer prognosis. As mentioned above, the disparity in FUS/FUS oncogenic vs. tumor-suppressive roles may be attributed to the complex molecular pathways associated with FUS regulation in different cancer types. In the context of cervical cancer, owing to our prospective dataset, this study suggest that FUS acts as a tumor suppressor. Low cost approaches such as immunohistochemistry can be used in clinical practice to determine FUS protein expression in cervical cancer specimens, which as demonstrated here may be a predictor of longer survival in advanced cases. Confirmatory data from larger studies is pending.

\section{Declarations}

\section{Author Contributions Statement}

Conception and design: Ana Maria Dias Fachini, Antonio Carlos Zuliani, Maria Cecília Ramiro Talarico, Lara Termini, Silvia Helena RabeloSantos, Luiz Carlos Zeferino.

Collection and assembly of data: Ana Maria Dias Fachini, Maria Cecília Ramiro Talarico, Rafaella Almeida Lima Nunes.

Page $4 / 10$ 
Data analysis and interpretation: Ana Maria Dias Fachini, Luis Otávio Sarian, Larissa Bastos Eloy da Costa, Luiz Carlos Zeferino.

Manuscript writing: all authors.

Final approval of manuscript: all authors.

\section{Author's disclosures of Potencial Conflicts of Interest}

The authors indicated no potencial conflicts of interest.

\section{References}

1. McDevitt, S., Rusanov, T., Kent, T., Chandramouly, G. \& Pomerantz, R. T. How RNA transcripts coordinate DNA recombination and repair. Nat Commun [Internet]. 2018;9(1):1091. Available from: http://www.ncbi.nlm.nih.gov/pubmed/29545568

2. Moynahan, M. E. \& Jasin, M. Mitotic homologous recombination maintains genomic stability and suppresses tumorigenesis. Nat Rev Mol Cell Biol [Internet]. 2010 Mar;11(3):196-207. Available from: http://www.ncbi.nlm.nih.gov/pubmed/20177395

3. Lagier-Tourenne, C., Polymenidou, M. \& Cleveland, D. W. TDP-43 and FUS/TLS: emerging roles in RNA processing and neurodegeneration. Hum Mol Genet [Internet]. 2010 Apr 15;19(R1):R46-64. Available from: http://www.ncbi.nlm.nih.gov/pubmed/20400460

4. Wang, W-Y. et al. Interaction of FUS and HDAC1 regulates DNA damage response and repair in neurons. Nat Neurosci [Internet]. 2013 Oct;16(10):1383-91. Available from: http://www.ncbi.nlm.nih.gov/pubmed/24036913

5. Mastrocola, A. S., Kim, S. H., Trinh, A. T., Rodenkirch, L. A. \& Tibbetts, R. S. The RNA-binding protein fused in sarcoma (FUS) functions downstream of poly(ADP-ribose) polymerase (PARP) in response to DNA damage.J Biol Chem. 2013

6. Rulten, S. L. et al. PARP-1 dependent recruitment of the amyotrophic lateral sclerosis-associated protein FUS/TLS to sites of oxidative DNA damage. Nucleic Acids Res [Internet]. 2014 Jan;42(1):307-14. Available from:

http://www.ncbi.nlm.nih.gov/pubmed/24049082

7. Shang, Y. \& Huang, E. J. Mechanisms of FUS mutations in familial amyotrophic lateral sclerosis. Brain Res [Internet]. 2016;1647:6578. Available from: http://www.ncbi.nlm.nih.gov/pubmed/27033831

8. Chen, R. X. et al. Circular RNA circRNA_0000285 promotes cervical cancer development by regulating FUS.Eur Rev Med Pharmacol Sci. 2019

9. He, Z. et al. FUS/circ_002136/miR-138-5p/SOX13 feedback loop regulates angiogenesis in Glioma. J Exp Clin Cancer Res [Internet]. 2019 Feb 8;38(1):65. Available from: http://www.ncbi.nlm.nih.gov/pubmed/30736838

10. Spitzer, J. I. et al. mRNA and protein levels of FUS, EWSR1, and TAF15 are upregulated in liposarcoma. Genes Chromosomes Cancer [Internet]. 2011 May;50(5):338-47. Available from: http://www.ncbi.nlm.nih.gov/pubmed/21344536

11. Xiong, D. et al. Elevated FUS/TLS expression is negatively associated with E-cadherin expression and prognosis of patients with nonsmall cell lung cancer. Oncol Lett [Internet]. 2018 Aug;16(2):1791-800. Available from:

http://www.ncbi.nlm.nih.gov/pubmed/30008867

12. Kwiatkowski, T. J. et al. Mutations in the FUS/TLS gene on chromosome 16 cause familial amyotrophic lateral sclerosis. Science [Internet]. 2009 Feb 27;323(5918):1205-8. Available from: http://www.ncbi.nlm.nih.gov/pubmed/19251627

13. Haile, S., Lal, A., Myung, J-K. \& Sadar, M. D. FUS/TLS is a co-activator of androgen receptor in prostate cancer cells. PLoS One [Internet]. 2011;6(9):e24197. Available from: http://www.ncbi.nlm.nih.gov/pubmed/21909421

14. Pecorelli, S. \& FIGO COMMITTEE ON GYNECOLOGIC ONCOLOGY Revised FIGO staging for carcinoma of the vulva, cervix, and endometrium.Int J Gynecol Obstet. 2009

15. Zuliani, A. C. et al. Concomitant cisplatin plus radiotherapy and high-dose-rate brachytherapy versus radiotherapy alone for stage IIIB epidermoid cervical cancer: A randomized controlled trial.J Clin Oncol. 2014

16. Fachini, A. M. D. et al. Long-term outcomes of concomitant cisplatin plus radiotherapy versus radiotherapy alone in patients with stage IIIB squamous cervical cancer: A randomized controlled trial. Gynecol Oncol [Internet]. 2021 Feb;160(2):379-83. Available from: http://www.ncbi.nlm.nih.gov/pubmed/33341239

17. Schneider, C. A., Rasband, W. S. \& Eliceiri, K. W. NIH Image to ImageJ: 25 years of image analysis. Nat Methods [Internet]. 2012 Jul;9(7):671-5. Available from: http://www.ncbi.nlm.nih.gov/pubmed/22930834

Page 5/10 
18. A language and environment for statistical computing [Internet]. Vienna, Austria: R Foundation for Statistical Computing; 2020. Available from: https://www.r-project.org/

19. Yamamoto, I., Azuma, Y. \& Yamaguchi, M. Cancer-related genes and ALS. Front Biosci (Landmark Ed [Internet]. 2019;24:1241-58. Available from: http://www.ncbi.nlm.nih.gov/pubmed/31136977

20. Suurmeijer, A. J. H. et al. A morphologic and molecular reappraisal of myoepithelial tumors of soft tissue, bone, and viscera with EWSR1 and FUS gene rearrangements. Genes Chromosomes Cancer [Internet]. 2020;59(6):348-56. Available from: http://www.ncbi.nlm.nih.gov/pubmed/31994243

21. Tan, A. Y. \& Manley, J. L. TLS/FUS: a protein in cancer and ALS. Cell Cycle [Internet]. 2012 Sep 15;11(18):3349-50. Available from: http://www.ncbi.nlm.nih.gov/pubmed/22918236

22. Ghanbarpanah, E., Kohanpour, M. A., Hosseini-Beheshti, F., Yari, L. \& Keshvari, M. Structure and function of FUS gene in prostate cancer. Bratisl Lek Listy [Internet]. 119(10):660-3. Available from: http://www.ncbi.nlm.nih.gov/pubmed/30345776

23. Brooke, G. N. et al. FUS/TLS is a novel mediator of androgen-dependent cell-cycle progression and prostate cancer growth. Cancer Res [Internet]. 2011 Feb 1;71(3):914-24. Available from: http://www.ncbi.nlm.nih.gov/pubmed/21169411

24. Ma, J. et al. MiR-378 promotes the migration of liver cancer cells by down-regulating Fus expression. Cell Physiol Biochem [Internet]. 2014;34(6):2266-74. Available from: http://www.ncbi.nlm.nih.gov/pubmed/25562172

25. Bao, L. et al. A FUS-LATS1/2 Axis Inhibits Hepatocellular Carcinoma Progression via Activating Hippo Pathway. Cell Physiol Biochem [Internet]. 2018;50(2):437-51. Available from: http://www.ncbi.nlm.nih.gov/pubmed/30308519

26. Zhou, Z. et al. Targeting Hippo pathway by specific interruption of YAP-TEAD interaction using cyclic YAP-like peptides. FASEB J [Internet]. 2015 Feb;29(2):724-32. Available from: http://www.ncbi.nlm.nih.gov/pubmed/25384421

\section{Tables}


Table 1

Expression of FUS protein according to patient's age, tumor grade, treatment performed and toxicity

\begin{tabular}{|c|c|c|c|c|c|c|c|c|c|c|c|}
\hline & \multicolumn{3}{|c|}{ Staining intensity } & \multicolumn{4}{|c|}{ Percentage of stained cells } & & \multicolumn{3}{|c|}{$\begin{array}{l}\text { Average expression of } 3 \\
\text { fields }\end{array}$} \\
\hline & & Weak & Moderate/Strong & & $<50 \%$ & $\begin{array}{l}50- \\
75 \%\end{array}$ & $>90 \%$ & & Low & High & \\
\hline & $\mathrm{n}$ & $\mathrm{n}(\%)$ & $\mathrm{n}(\%)$ & $\mathrm{p}$ & $\mathrm{n}(\%)$ & $\mathrm{n}(\%)$ & $\mathrm{n}(\%)$ & $p$ & $\mathrm{n}(\%)$ & $\mathrm{n}(\%)$ & $p$ \\
\hline$<50$ & 19 & $13(27.1)$ & $6(53.8)$ & \multirow{2}{*}{$0.23^{a}$} & $10(27.0)$ & $5(55.6)$ & $4(26.7)$ & \multirow{2}{*}{$0.27^{\beta}$} & $5(19.2)$ & $14(40)$ & \multirow[t]{2}{*}{$0.12^{a}$} \\
\hline$\geq 50$ & 41 & $35(72.9)$ & $7(46.2)$ & & $27(73.0)$ & $4(44.4)$ & $11(73.3)$ & & $21(80.8)$ & $21(60)$ & \\
\hline \multicolumn{12}{|c|}{$\begin{array}{l}\text { Tumor } \\
\text { grade* }\end{array}$} \\
\hline 1 & 4 & $3(6.4)$ & $1(7.7)$ & \multirow[t]{3}{*}{$1.00^{\beta}$} & $1(2.8)$ & $2(22.2)$ & $1(6.7)$ & \multirow[t]{3}{*}{$0.28^{\beta}$} & $0(0.0)$ & $4(11.4)$ & \multirow[t]{3}{*}{$0.15^{\beta}$} \\
\hline 2 & 45 & $35(74.5)$ & $10(76.9)$ & & 28(77.8) & $5(55.6)$ & $12(80.0)$ & & 19(76.0) & $26(74.3)$ & \\
\hline 3 & 11 & $9(19.1)$ & $2(15.4$ & & $7(19.4)$ & $2(22.2)$ & 2(13.3) & & $6(24.0)$ & $5(14.3)$ & \\
\hline \multicolumn{12}{|c|}{ Treatment } \\
\hline CRT & 31 & $23(47.9)$ & $8(61.5)$ & \multirow[t]{2}{*}{$0.57^{a}$} & $16(43.2)$ & $8(88.9)$ & $7(46.7)$ & \multirow[t]{2}{*}{$0.05^{\beta}$} & $12(46.2)$ & $19(54.3)$ & \multirow[t]{2}{*}{$0.71^{a}$} \\
\hline RT & 30 & $25(52.1)$ & $5(38.5)$ & & $21(56.8)$ & $1(11.1)$ & 8(53.3) & & $14(53.8)$ & $16(45.7)$ & \\
\hline \multicolumn{12}{|c|}{$\begin{array}{l}\text { Acute } \\
\text { toxicity* }\end{array}$} \\
\hline Yes & 16 & $13(28.3)$ & $3(27.3)$ & \multirow[t]{2}{*}{$1.00^{\beta}$} & 12(33.3) & $1(12.5)$ & $3(23.1)$ & \multirow[t]{2}{*}{$0.57^{\beta}$} & $10(40.0)$ & $6(18.8)$ & \multirow[t]{2}{*}{$0.14^{a}$} \\
\hline No & 41 & $33(71.7)$ & $8(72.7)$ & & $24(66.7)$ & $7(87.5)$ & $10(76.9)$ & & $15(60.0)$ & $26(81.2)$ & \\
\hline \multicolumn{12}{|c|}{$\begin{array}{l}\text { Late } \\
\text { toxicity* }\end{array}$} \\
\hline Yes & 25 & $26(44.7)$ & $8(33.3)$ & \multirow[t]{2}{*}{$0.53^{\beta}$} & $17(45.9)$ & $2(22.2)$ & $6(46.2)$ & \multirow[t]{2}{*}{$0.44^{\beta}$} & $10(38.5)$ & $15(45.5)$ & \multirow[t]{2}{*}{$0.78^{a}$} \\
\hline No & 34 & $21(55.3)$ & $4(66.7)$ & & $20(54.1)$ & $7(77.8)$ & 7(53.8) & & $16(61.5)$ & $18(54.5)$ & \\
\hline \multicolumn{12}{|c|}{ CRT = Chemoradiotherapy, RT = Radiotherapy } \\
\hline \multicolumn{12}{|c|}{$\begin{array}{l}\text { *Some cases had no available information of tumor grade, acute toxicity and late toxicity, therefore cases with this information } \\
\text { available were presented. }\end{array}$} \\
\hline
\end{tabular}


Table 2

Expression of FUS protein according to the occurrence of relapse, local recurrence, distant recurrence, death and death due to cancer

\begin{tabular}{|c|c|c|c|c|c|c|c|c|c|c|c|}
\hline & \multicolumn{3}{|c|}{ Staining intensity } & \multicolumn{5}{|c|}{ Percentage of stained cells } & \multicolumn{3}{|c|}{$\begin{array}{l}\text { Average expression of } 3 \\
\text { fields }\end{array}$} \\
\hline & & Weak & Moderate/Strong & & $<50 \%$ & $\begin{array}{l}50- \\
75 \%\end{array}$ & $>90 \%$ & & Low & High & \\
\hline & $\mathrm{n}$ & $\mathrm{n}(\%)$ & $\mathrm{n}(\%)$ & $p$ & $\mathrm{n}(\%)$ & $\mathrm{n}(\%)$ & $\mathrm{n}(\%)$ & $p$ & $\mathrm{n}(\%)$ & $\mathrm{n}(\%)$ & $p$ \\
\hline \multicolumn{12}{|c|}{ Relapse } \\
\hline Yes & 26 & $20(41.7)$ & $6(46.2)$ & \multirow[t]{2}{*}{$1.00^{\mathrm{a}}$} & $17(45.9)$ & $3(33.3)$ & $6(40.0)$ & \multirow[t]{2}{*}{$0.81^{\beta}$} & $15(57.7)$ & $11(31.4)$ & \multirow[t]{2}{*}{$0.07^{a}$} \\
\hline No & 35 & $28(58.3)$ & $7(53.8)$ & & $20(54.1)$ & $6(66.7)$ & $9(60.0)$ & & $11(42.3)$ & $24(68.6)$ & \\
\hline \multicolumn{12}{|c|}{$\begin{array}{l}\text { Local } \\
\text { recurrence }\end{array}$} \\
\hline Yes & 13 & $10(20.8)$ & $3(23.1)$ & \multirow[t]{2}{*}{$1.00^{\beta}$} & $10(27.0)$ & $2(22.2)$ & $1(6.7)$ & \multirow[t]{2}{*}{$0.32^{\beta}$} & $9(34.6)$ & $4(11.4)$ & \multirow[t]{2}{*}{$0.05^{\beta}$} \\
\hline No & 48 & $38(79.2)$ & $10(76.9)$ & & $27(73.0)$ & $7(77.8)$ & $14(93.3)$ & & $17(65.4)$ & $31(88.6)$ & \\
\hline \multicolumn{12}{|c|}{$\begin{array}{l}\text { Distant } \\
\text { recurrence }\end{array}$} \\
\hline Yes & 18 & $12(25.0)$ & $6(46.2)$ & \multirow{2}{*}{$0.25^{a}$} & $9(24.3)$ & $3(33.3)$ & $6(40.0)$ & \multirow[t]{2}{*}{$0.52^{\beta}$} & $7(26.9)$ & 11(31.4) & \multirow[t]{2}{*}{$0.92^{a}$} \\
\hline No & 43 & $36(75.0)$ & $7(53.8)$ & & $28(75.7)$ & $6(66.7)$ & $9(60.0)$ & & 19(73.1) & $24(68.6)$ & \\
\hline \multicolumn{12}{|c|}{ Death } \\
\hline Yes & 34 & $26(54.2)$ & $8(61.5)$ & \multirow{2}{*}{$0.87^{a}$} & 18(48.6) & 7(77.8) & $9(60.0)$ & \multirow{2}{*}{$0.26^{a}$} & $16(61.5)$ & 18(51.4) & \multirow[t]{2}{*}{$0.59^{a}$} \\
\hline No & 27 & $22(45.8)$ & $5(38.5)$ & & $19(51.4)$ & $2(22.2)$ & $6(40.0)$ & & $10(38.5)$ & $17(48.6)$ & \\
\hline \multicolumn{12}{|c|}{$\begin{array}{l}\text { Death due } \\
\text { to cancer }\end{array}$} \\
\hline Yes & 27 & $20(76.9)$ & $7(87.5)$ & \multirow[t]{2}{*}{$1.00^{\beta}$} & $16(88.9)$ & $5(71.4)$ & $6(66.7)$ & \multirow[t]{2}{*}{$0.38^{\beta}$} & 15(93.8) & $12(66.7)$ & \multirow[t]{2}{*}{$0.09^{\beta}$} \\
\hline No & 7 & $6(23.1)$ & $1(12.5)$ & & $2(11.1)$ & $2(28.6)$ & $3(33.3)$ & & $1(6.2)$ & 6(33.3) & \\
\hline
\end{tabular}


Table 3

Multivariate Cox regression analysis for disease-free survival, overall survival and overall survival due to cancer according to patient's age, tumor grade, treatment performed and average expression of 3 fields

\begin{tabular}{|c|c|c|c|c|c|c|c|c|c|c|}
\hline \multirow[t]{2}{*}{ Categories } & & \multicolumn{3}{|c|}{ Disease-free survival } & \multicolumn{3}{|c|}{ Overall Survival } & \multicolumn{3}{|c|}{ Cancer-related survival } \\
\hline & & $\mathrm{HR}^{\#}$ & $95 \% \mathrm{Cl}$ & $\begin{array}{l}\mathrm{p}- \\
\text { value }\end{array}$ & $\mathrm{HR}^{\# \#}$ & $95 \% \mathrm{Cl}$ & $\begin{array}{l}\mathrm{p} \text { - } \\
\text { value }\end{array}$ & $\mathrm{HR}^{\# \# \#}$ & $95 \% \mathrm{Cl}$ & $\begin{array}{l}\mathrm{p}- \\
\text { value }\end{array}$ \\
\hline \multirow[t]{2}{*}{ Age } & $\geq 50$ & Ref. & & & Ref. & & & Ref. & & \\
\hline & $<50$ & 3.45 & $\begin{array}{l}(1.26 \text { to } \\
9.45)\end{array}$ & 0.01 & 1.92 & $\begin{array}{l}(0.80 \text { to } \\
4.58)\end{array}$ & 0.14 & 3.83 & $\begin{array}{l}(1.41 \text { to } \\
10.42)\end{array}$ & 0.008 \\
\hline \multirow[t]{2}{*}{ Tumor grade* } & $\begin{array}{l}1 \text { and } \\
2\end{array}$ & Ref. & & & Ref. & & & Ref. & & \\
\hline & 3 & 1.49 & $\begin{array}{l}(0.56 \text { to } \\
3.98)\end{array}$ & 0.42 & 1.39 & $\begin{array}{l}(0.62 \text { to } \\
3.11)\end{array}$ & 0.42 & 1.41 & $\begin{array}{l}(0.55 \text { to } \\
3.61)\end{array}$ & 0.46 \\
\hline \multirow[t]{2}{*}{ Treatment } & CRT & Ref. & & & Ref. & & & Ref. & & \\
\hline & RT & 2.30 & $\begin{array}{l}(1.01 \text { to } \\
5.39)\end{array}$ & 0.05 & 1.24 & $\begin{array}{l}(0.59 \text { to } \\
2.58)\end{array}$ & 0.56 & 2.03 & $\begin{array}{l}(0.89 \text { to } \\
4.64)\end{array}$ & 0.09 \\
\hline \multirow{2}{*}{$\begin{array}{l}\text { Average expression of } 3 \\
\text { fields }\end{array}$} & Low & Ref. & & & Ref. & & & Ref. & & \\
\hline & High & 0.31 & $\begin{array}{l}0.12 \text { to } \\
0.77\end{array}$ & 0.01 & 0.65 & $\begin{array}{l}(0.29 \text { to } \\
1.46)\end{array}$ & 0.30 & 0.41 & $\begin{array}{l}(0.17 \text { to } \\
0.98)\end{array}$ & 0.04 \\
\hline \multicolumn{11}{|c|}{ *The evaluation of FUS expression was based on the percentage of stained cells and the staining intensity } \\
\hline \multicolumn{11}{|c|}{ \#HR (Hazard Ratio) = 26 patients relapsed during observation. } \\
\hline \multicolumn{11}{|c|}{ \#\# 34 patients died during observation. } \\
\hline \multicolumn{11}{|c|}{ \#\#\#27 patients died due to cancer during observation. } \\
\hline \multicolumn{11}{|c|}{$\mathrm{Cl}=$ confidence interval of $95 \%$} \\
\hline
\end{tabular}

\section{Figures}




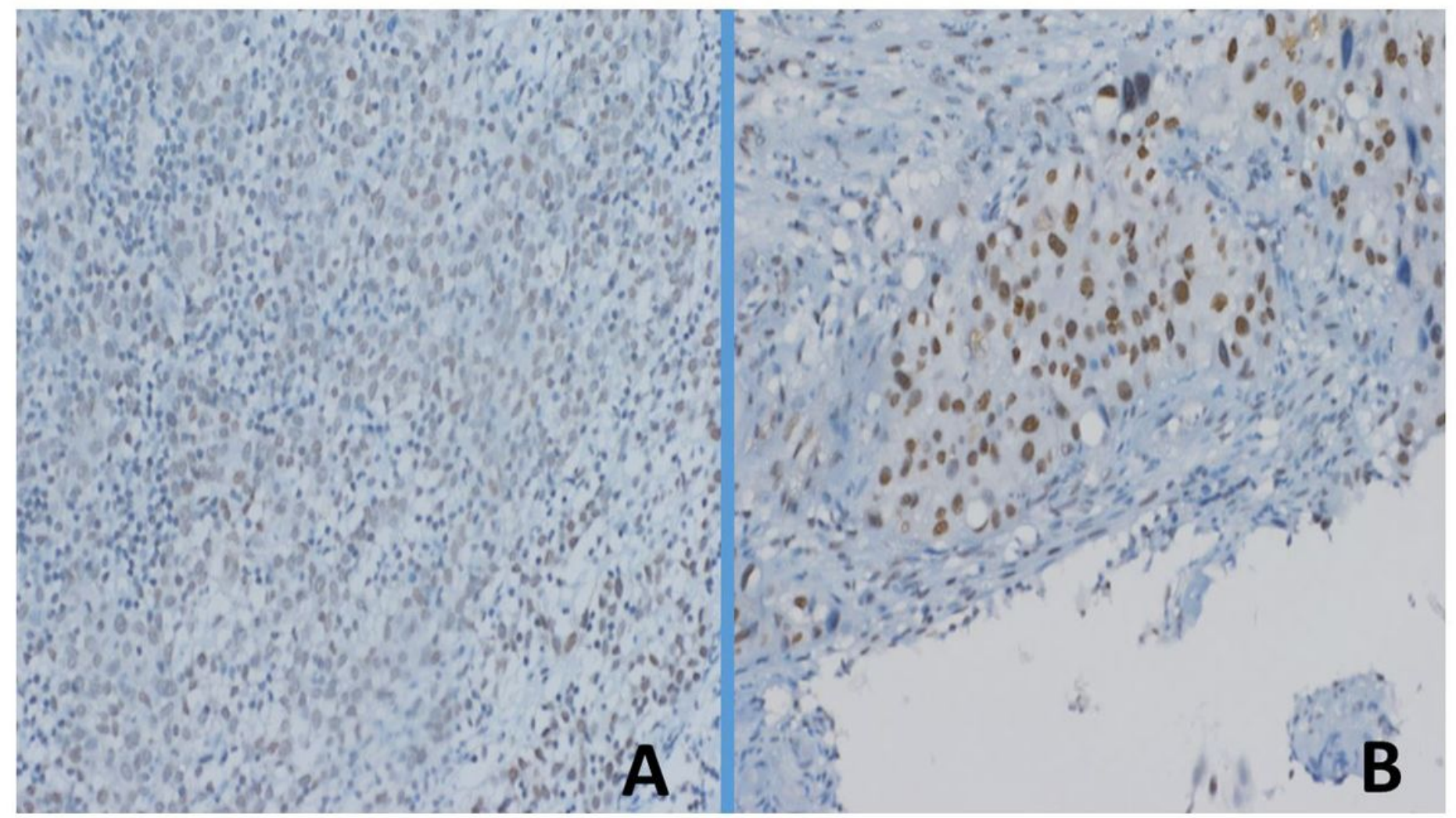

\section{Figure 1}

A) Squamous cell carcinoma with weak nuclear FUS staining (4x). B) Nests of neoplastic cells exhibiting strong and diffuse nuclear FUS expression. 